\title{
Prevalence and risk factors for brucellosis in prolonged fever patients in post-conflict Northern Uganda
}

\author{
Harriet N Muloki ${ }^{1,2}$, Joseph Erume ${ }^{2}$, David O Owiny ${ }^{2}$, Joseph M Kungu ${ }^{3}$, \\ Jesca Nakavuma ${ }^{2}$, Duncan Ogeng ${ }^{1}$, George W Nasinyama ${ }^{2}$
}

1. Faculty of Agriculture and Environment, Gulu University. P. O. Box 166, Gulu, Uganda.

2. College of Veterinary Medicine, Animal Resources and Biosecurity, Makerere University,

P. O. Box 7062, Kampala, Uganda; Current Address: Kampala International University,

P.O Box 20000, Kampala, Uganda.

3. National Livestock Resources Research Institute, P.O.Box 96, Tororo.

\begin{abstract}
Background: Brucellosis is a disease with significant public and economic implications but strategies for controlling this disease remain problematic.

Objectives: This study sought to determine the sero-prevalence of brucellosis in prolonged fever patients and to identify modifiable risk factors for the infection in humans in post conflict Northern Uganda.

Methods: The study employed a cross-sectional method among prolonged fever patients who had visited selected health facilities in the study districts in Northern Uganda. Sero-prevalence of brucellosis was calculated for i-ELISA IgG/IgM. A structured questionnaire was used to obtain data on possible risk factors for brucellosis. Associations between sero-prevalence and risk factors were measured using the Odds Ratio.

Results: Brucellosis was confirmed in $18.7 \%$ of the 251 patients that tested positive for the disease, with the rapid Brucella Plate Agglutination Test, and ages 10-84 years (median age 47+0.86). Sex ( $\mathrm{p}=0.001$; OR 3.79; 95\% CI $1.75-8.24$ ), rearing livestock ( $\mathrm{p}<0.005$; OR 8.44; 95\% CI 2.84-25.03) and consumption of unpasteurised milk ( $\mathrm{p}=0.023$; OR 2.57; 95\% CI 1.14-5.80) were factors associated with brucellosis.

Conclusion: Control of brucellosis in animals, training and sensitisation of the community on brucellosis is needed to stimulate action on human brucellosis control.

Keywords: Brucellosis, human, fever, prevalence, Uganda, zoonosis.

DOI: https://dx.doi.org/10.4314/ahs.v18i1.4

Cite as: Muloki HN, Erume J, Owiny DO, Kungu JM, Nakavuma J, Ogeng D, Nasinyama GW. Prevalence and risk factors for brucellosis in prolonged fever patients in post-conflict Northern Uganda. Afri Health Sci 2018;18(1):22-28. https:// dx.doi.org/10.4314/abs.v18i1.4
\end{abstract}

\section{Introduction}

Brucellosis is a widespread zoonosis of both public health and economic concern ${ }^{1-3}$. The global burden of

\section{Corresponding author: \\ George W Nasinyama, Kampala International University, P. O. Box 2000, Kampala, Uganda. \\ Tel. +256772492865; \\ Email: gwnasinyama@gmail.com}

human brucellosis remains enormous with more than 500,000 new infections occurring annually worldwide 4 . Brucellosis is caused by organisms of genus Brucella with six pathogenic species of which four are known to cause human disease ${ }^{5}$. B. melitensis cause the most severe human disease, followed by B. suis, B. abortus and B. canis $^{6}$. In humans brucellosis is transmitted by direct or indirect contact with infected animals and their products ${ }^{7}$. Inhalation of infectious aerosols and ingestion of raw milk or unpasteurized dairy products or meat from an infected animal is the most frequent route of infection ${ }^{8,9}$. Major 
symptoms for brucellosis in humans include; undulant fever, weight loss, back pain, fatigue and night sweats ${ }^{1}$.

Diagnosis of brucellosis is impossible without laboratory confirmation involving a combination of methods ${ }^{10}$. Blood culture for Brucellae isolation remains the gold standard ${ }^{11}$ but may not provide a positive result for all patients $^{12}$. Nucleic acid amplification can provide rapid detection and confirmation of Brucella ${ }^{13}$ but standardization of extraction methods, infrastructure, equipment and expertise are still lacking ${ }^{6}$. Bacteriological and genomic limitations make serology the most practical and useful tool for brucellosis diagnosis ${ }^{11}$. The serological tests like Rose Bengal Plate Agglutination Test (RBPT), standard tube agglutination test (STAT), Enzyme Linked Immuno-Sorbent Assay (ELISA) and fluorescence polarization assay (FPA) among others have been applied in human brucellosis diagnosis ${ }^{11,13,14}$. However, STAT remains the most popular serological test used ${ }^{14}$ and titres of 1:160 and above are considered diagnostic ${ }^{13}$. Nevertheless, STAT has limitations making ELISA to be most acceptable for diagnosing human brucellosis ${ }^{11,15,16}$. Mantur and others ${ }^{11}$ found ELISA to be more sensitive than STAT in detecting brucellosis in both acute and chronic cases while sensitivity and specificity of ELISA was reported to be $71.3 \%$ and $100 \%$ respectively. Araj and others ${ }^{15}$ reported sensitivities of $100 \%$ and $91 \%$ for $\operatorname{IgM}$ and $\operatorname{IgG}$ ELISAs, respectively, and a specificity of $100 \%$ for both assays. In addition, Asaad and other workers ${ }^{16}$ reported sensitivities of ELISA IgM and IgG to be $85.2 \%$ and $96.3 \%$,respectively and specificity of $100 \%$ for each..

Human brucellosis occurs widely in Uganda ${ }^{8,17,18}$. A recent study carried out in Gulu district in Northern Uganda reported individual animal and herd level sero-prevalence of bovine brucellosis to be $6 \%$ and $19 \%$, respectively. Restocking and communal grazing were the major risk factors associated with the disease ${ }^{19}$. Northern Uganda is under rehabilitation with promotion of livestock rearing and re-stocking. To date, no study has described human brucellosis in post conflict Northern Uganda, a region that witnessed a total breakdown in socio-economic infrastructure, governance and services. The aim of this study was to estimate the sero-prevalence of human brucellosis in prolonged fever patients and identify modifiable risk factors for the infection in post-conflict Northern Uganda. This study considered ELISA IgG/IgM which is reported as the most specific serology test against SAT.

\section{Methods}

\section{Ethics and consent to participate statement}

Ethical approval was obtained from Gulu University Research Council (Ref No: GU/IRC/02/07/13) and the Uganda National Council of Science and Technology (UNCST) Reference No: HS 1442. Written consent/assent was sought from all individuals before enrolment.

The study was carried out in post-conflict areas of Northern Uganda, in the districts of Apac, Gulu, Lira and Pader covering up to nine percent of the country's $236,040 \mathrm{Km}^{2}$ area size.

\section{Study design and enrolment of study patients}

A cross-sectional study was conducted from March 2014 to February 2015. Study patients were selected from 17 out of the 244 public and private health facilities in the study area ${ }^{20-23}$. The health facilities were purposively selected basing on capacity to test for brucellosis and willingness to participate in the study. The study targeted patients with fever, headache, joint pain, malaise, backache, fatigue and loss of appetite visiting study health facilities. Medical personnel in the out patient department (OPD) identified suspects and tested them with the rapid Brucella Plate Agglutination Test (BPAT). The sample size for study subjects was calculated using the formula for cross sectional survey as described before ${ }^{24}$ at $5 \%$ desired precision and $95 \%$ confidence interval with prevalence of human brucellosis in Uganda estimated at $18 \%{ }^{8}$.

\section{Laboratory investigation}

To determine the sero-prevalence of brucellosis in prolonged fever patients, STAT 1: 160 was used as the standard serological test against SAT 1: 320, iELISA IgG, iELISA IgM and iELISA IgG/IgM. Only BPAT positive samples from consented subjects were further investigated. All subjects were briefed on the objectives of the study, and signed a consent form. Cephalic vein blood was collected into sterile silicon-coated tubes without anticoagulant for serum harvesting after 24 hours at room temperature. The serum was transported on ice to Makerere University, College of Veterinary Medicine, Animal Resources and Biosecurity (CoVAB) and kept at $-20^{\circ} \mathrm{C}$. Samples were analysed using STAT (Remel kit, Europe) and i-ELISA (Vircell S.L, Santa Fe, and Granada, Spain) according to the manufacturers' guidelines. To improve sensitivity, results for i-ELISA, were interpreted in parallel, with any IgG or IgM positive test reported as positive 
for i-ELISA as described previously ${ }^{17}$. A structured questionnaire was used to obtain data on possible risk factors for human brucellosis. Information collected from study subjects included age, gender, district of origin, education level, rearing livestock, knowledge on brucellosis transmission and practice of consumption of unpasteurized milk/milk products.

\section{Statistical analysis}

Sero-prevalence of brucellosis in humans was calculated for both STAT and i-ELISA (IgG and IgM). Associations between sero-prevalence of human brucellosis and mod- ifiable risk factors were assessed with a Chi-square test and Odds Ratio at 95\% confidence interval using SPSS, (SPSS Inc. Chicago, USA Version 16.0). Variables with $\mathrm{p} \leq 0.1$ at univariable analysis were included in a multivariable logistic regression model. The backward selection procedure was used to identify factors for the final models. Goodness of fit for the final model was assessed using Hosmer and Lemeshow goodness of fit test.

\section{Results}

A total of 251 prolonged fever patients aged 10-84 years (median age $47.0 \pm 0.86$ ) were enrolled in the study (Fig 1).

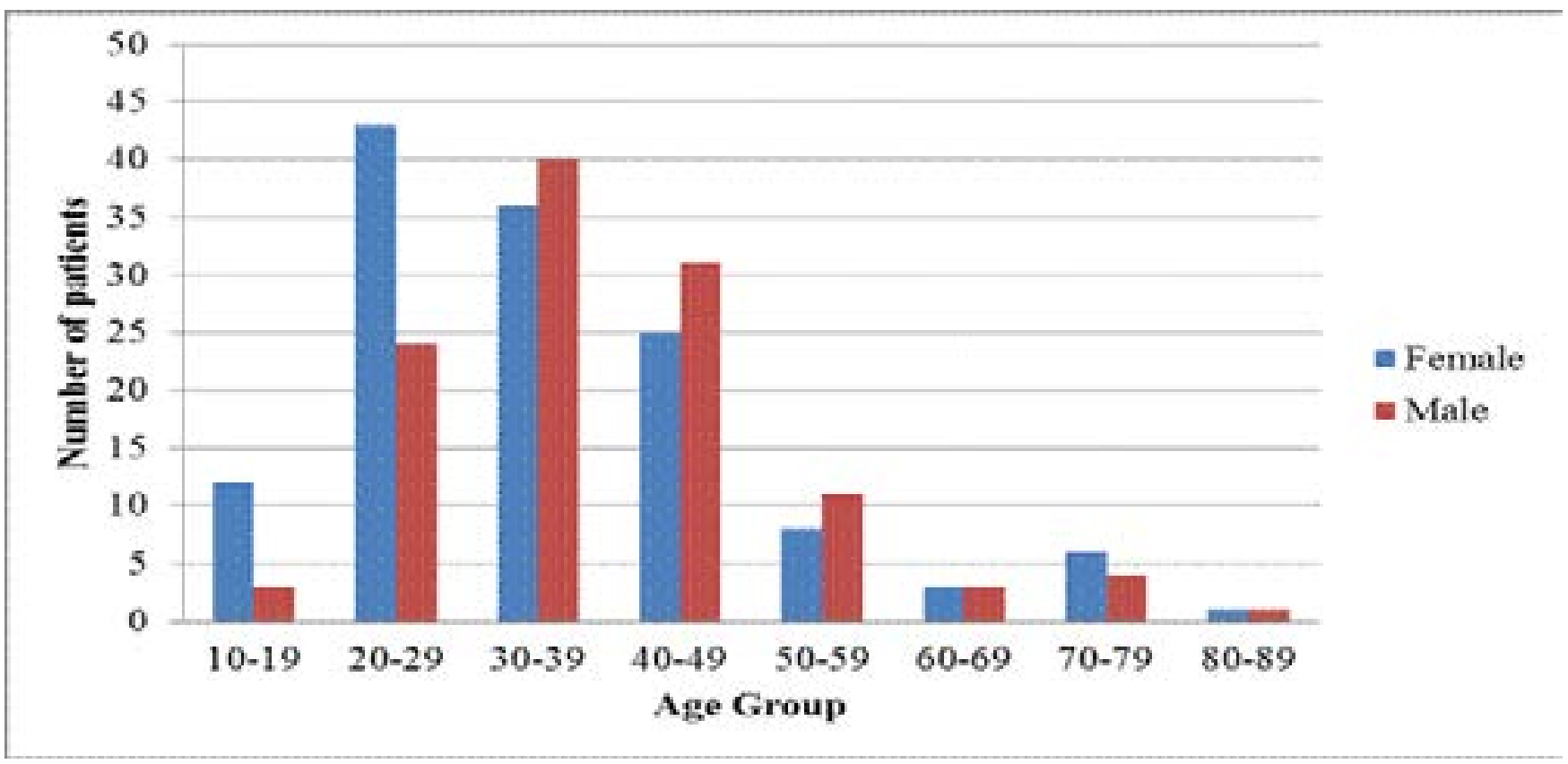

Figure 1: Distribution of study patients by gender and age group

Up to 207 study subjects were from government and 44 from private health facilities. All serological tests showed significant $(\mathrm{p}<0.05)$ differences in brucellosis sero-positivity between health facilities, sex and keeping livestock. In addition brucellosis sero-positivity differed significant- ly $(\mathrm{p}<0.05)$ with consumption of milk and milk products basing on STAT 1:160, 1:320 and i-ELISA IgM, but did not differ basing on i-ELISA IgG. There was no difference in sero-positivity with education level ( $p>0.05)$ basing on all the four serological tests (Table 1). 
Table 1: Sero-prevalence of brucella among prolonged fever patients

\begin{tabular}{|c|c|c|c|c|c|c|}
\hline \multirow[b]{2}{*}{ Variable } & \multirow[b]{2}{*}{ Category } & \multirow[b]{2}{*}{ Frequency } & \multicolumn{4}{|c|}{ Test Results (\%,p-value), $n=251$} \\
\hline & & & STAT 1:160 & STAT1:320 & i-ELISA IgG & $\begin{array}{l}\text { i-ELISA } \\
\text { IgM }\end{array}$ \\
\hline \multirow[t]{2}{*}{ Health facility } & Government & 207 & $32.7(0.000)^{*}$ & $17.5(0.026)^{*}$ & $12.7(0.005)^{*}$ & $10.8(0.039)^{*}$ \\
\hline & Private & 44 & 2.0 & 1.2 & 0.0 & 0.4 \\
\hline \multirow[t]{2}{*}{ Gender } & Male & 117 & $19.9(0.012)^{*}$ & $11.2(0.048)^{*}$ & $10.8(0.000)^{*}$ & $8.4(0.001)^{*}$ \\
\hline & Female & 134 & 14.7 & 7.5 & 1.9 & 2.8 \\
\hline \multirow{4}{*}{$\begin{array}{l}\text { Age category of } \\
\text { patients }\end{array}$} & Children & 8 & $0.8(0.887)$ & $0.0(0.0507)$ & $0.0(0.722)$ & $0.0(0.361)$ \\
\hline & Youth & 188 & 26.3 & 14.3 & 9.6 & 7.6 \\
\hline & Adult & 41 & 6.0 & 3.6 & 2.4 & 2.4 \\
\hline & Elderly & 14 & 1.6 & 0.8 & 0.8 & 1.2 \\
\hline Educational & $\leq$ Primary & 152 & $22.7(0.242)$ & $11.2(0.878)$ & $7.6(0.883)$ & $8.0(0.212)$ \\
\hline level & $>$ Primary & 99 & 12.0 & 7.5 & 5.1 & 3.2 \\
\hline \multirow[t]{2}{*}{ Keep livestock } & Yes & 145 & $29.9(0.000)^{*}$ & $16.3(0.000)^{*}$ & $11.1(0.000)^{*}$ & $10.4(0.000)^{*}$ \\
\hline & No & 106 & 4.8 & 2.4 & 1.6 & 0.8 \\
\hline \multirow{2}{*}{$\begin{array}{l}\text { Knowledge } \\
\text { Transmission }\end{array}$} & No & 231 & $31.5(0.601)$ & $16.7(0.453)$ & $11.6(0.753)$ & $9.2(0.040)^{*}$ \\
\hline & Yes & 20 & 3.2 & 2.0 & 1.1 & 2.0 \\
\hline \multirow{2}{*}{$\begin{array}{l}\text { Consume } \\
\text { pasteurised } \\
\text { Milk/milk } \\
\text { products }\end{array}$} & No & 151 & $27.1(0.000)^{*}$ & $17.1(0.000)^{*}$ & $9.6(0.066)$ & $9.2(0.012)^{*}$ \\
\hline & Yes & 100 & 7.6 & 1.6 & 3.1 & 2.0 \\
\hline
\end{tabular}

$* 5 \%$ level of significance

Basing on the parallel interpretation of either positive alence differed significantly $(\mathrm{p}<0.05)$ with gender, rearing i-ELISA IgG or IgM or both tests, brucellosis sero-prev- livestock and consumption of unpasteurised milk/milk products (Table 2).

Table 2. Relationship between the hypothesised risk factors for human brucellosis and sero-positivity based on i-ELISA IgG/IgM.

\begin{tabular}{|c|c|c|c|c|c|}
\hline Variable & Category & $\begin{array}{c}\% \text { test positive } \\
(n=251)\end{array}$ & $\chi^{2}$ & df & p-value \\
\hline \multirow[t]{2}{*}{ Gender } & Male & 14.3 & 20.89 & 1 & $<0.005^{*}$ \\
\hline & Female & 4.4 & & & \\
\hline \multirow[t]{2}{*}{ Age group } & $<30$ years & 5.2 & 3.15 & 1 & 0.076 \\
\hline & $>30$ years & 13.5 & & & \\
\hline \multirow[t]{2}{*}{ Education level } & $\leq$ Primary & 12.0 & 0.26 & 1 & 0.611 \\
\hline & $>$ Primary & 6.7 & & & \\
\hline \multirow[t]{2}{*}{ Keep livestock } & Yes & 17.1 & 26.95 & 1 & $<0.005^{*}$ \\
\hline & No & 1.6 & & & \\
\hline Knowledge on & Not Know & 14.3 & 1.82 & 1 & 0.178 \\
\hline Transmission & Knowledgeable & 3.4 & & & \\
\hline Consume milk & Unpasteurised & 14.7 & 8.32 & 1 & $0.004 *$ \\
\hline and milk products & Pasteurised & 4.0 & & & \\
\hline
\end{tabular}


Gender (OR 3.79; 95\% CI: 1.75-8.24), livestock rearing (OR 8.44; 95\% CI: 2.84-25.03) and consumption of unpasteurised milk (OR 2.57; 95\% CI: 1.14-5.80) were significantly associated with brucellosis. The model explained 30.9\% (NagelkerkeoR2) of the variance in brucellosis sero-prevalence and correctly classified $83.3 \%$ of the cases. The Odds of being brucella positive in males with prolonged fever were four times the Odds in females. Livestock rearing was highly associated with brucella sero-positivity and consumption of unpasteurised milk and milk products increased the likelihood of testing brucella sero-positive (Table 3).

\section{Table 3. Multivariable logistic regression of factors associated with human brucellosis in post-conflict northern Uganda}

\begin{tabular}{llccl}
\hline Variable & Category & $\begin{array}{c}\text { \% Sero- } \\
\text { positivity }(\mathrm{n}=251)\end{array}$ & $\begin{array}{l}\text { Odds } \\
\text { Ratios }(95 \% \mathrm{CI})\end{array}$ & p-values \\
\hline Gender & Male & 14.3 & $3.79(1.75-8.24)$ & $0.001^{*}$ \\
Female & 4.4 & & \\
Age group & $<30$ years & 5.2 & $1.73(0.80-3.75)$ & 0.164 \\
Keep livestock & $>30$ years & 13.5 & & \\
& Yes & 17.1 & $8.44(2.84-25.03)$ & $0.005^{*}$ \\
Consumption of & No & 1.6 & & \\
Milk/milk products & Unpasteurised & 14.7 & $2.57(1.14-5.80)$ & $0.023^{*}$ \\
\hline
\end{tabular}

* 5\% level of significance

\section{Discussion}

This is the first study to document the sero-prevalence of human brucellosis among patients with prolonged fever in Northern Uganda. The study showed sero-prevalence of human brucellosis in Northern Uganda to be 18.7\% with i- ELISA and 34.7\% with STAT (1:160). However, sero-positivity with STAT titres (1>1:320) was $18.7 \%$, an indication of active infection. This is not surprising since study subjects had come to seek medical attention with symptoms relating to brucellosis. This finding is comparable to a recent study ${ }^{17}$ which reported STAT sero-prevalence results not to be different $(p<0.05)$ from that for c-ELISA. Findings here support the use of ELISA tests for confirming brucellosis in low-income countries where brucellosis is endemic. This study showed men to be four times likely to test positive for brucellosis than women. In the current study, milking and grazing animals is a man's role thus men are more in contact with animals than women. This finding is supported by reports of epidemiological studies in other parts of the world where human brucellosis is considered an occupational disease ${ }^{25}$. In addition, reports show no sex-wise discrimination of brucellosis infection between male and female as both have equal susceptibility if provided with exposure to potential risk factors ${ }^{26}$. Nevertheless, the current study contradicts studies elsewhere which reported high prevalence of brucellosis among females than males ${ }^{25,27}$.

This study clearly shows livestock rearing $(\mathrm{p}<0.005)$ to be strongly associated with human brucellosis. Generally, livestock harbour brucellosis in a sub-clinical state and farm families are at high risk of exposure to the disease through contact with fluids of affected livestock or consumption of their unpasteurized products. This study is in agreement with Corbel $^{6}$ who pointed out that when animals are kept in close proximity to human habitat, the practice can result in brucella infection as people are in constant contact with infective materials. This study has also shown brucellosis sero-positivity to be highly associated with consumption of unpasteurised milk/milk products. This finding parallels another study ${ }^{28}$ which reported that significantly $(p<0.02)$ more sero-positive humans with a history of raw milk. This calls for increased awareness among the communities in post-conflict Northern Uganda about the dangers associated with drinking raw milk, among others. Since this study dealt with only sus- 
pected brucellosis patients and did not cover all health facilities, results need to be interpreted cautiously. However, the study has provided important information to support brucellosis control programs.

\section{Conclusion and recommendations}

Findings in this study show clearly that the sero-prevalence of human brucellosis among patients with prolonged fever is high (18.7\%). Rearing livestock and consumption of unpasteurised milk/milk products were factors associated with brucellosis. Strategies to control animal brucellosis and raising awareness about the consumption of unpasteurised milk and milk products are necessary to reduce the incidence of human infection in Northern Uganda. Innovative methods to sensitize the community on brucellosis and cost effective methods to control animal brucellosis are recommended.

\section{Authors' contributions}

HMN was involved in the development of the concept, study design, data collection, analysis, and writing of the paper. JE and DOO helped to develop the concept, supervised the study, and critically revised the paper. GWN participated in the study design and data interpretation, revised the paper and approved the final version. JMK participated in the acquisition of the data, revised the paper and approved the final version. DO and JN participated in the development of the concept study design and the drafting of the paper. All authors read and approved the final version of the paper.

\section{Acknowledgements}

We thank Gulu University ECART (Enhancing Capacity for Agricultural Research and Training), Netherlands Organization for Capacity Building in Higher Education (NUFFIC) and the International Centre for Development Oriented Research in Agriculture (ICRA) for the financial support. We thank all participants in health facilities and veterinary departments in the study districts, as well, the personnel in Makerere University, College of Veterinary Medicine, Animal Resources and Biosecuritycentral diagnostic.

\section{Conflict of interest}

None.

\section{References}

1. Sauret JM, Vilissova N. Human brucellosis. J Am Board Fam Pract [Internet]. 2002;15(5):401-6. Available from: http://www.ncbi.nlm.nih.gov/pubmed/12350062

2. Purcell, Bret K.; Hoover, David L. and Friedlander AM. Chapter 9, Brucellosis. Med Asp Biol Warf. 2007;18598 PubMed .

3. OIE. Bovine Brucellosis. OIE Terr Man. 2009. 2009;(May):1-35.

4. Pappas G, Papadimitriou P, Akritidis N, Christou L, Tsianos E V. The new global map of human brucellosis. Lancet Infect Dis. 2006;6(2):91-9. PubMed

5. Moreno E, Cloeckaert A, Moriyón I. Brucella evolution and taxonomy. Vet Microbiol. 2002;90(1-4):209-27. 6. Brucellosis in humans and animals Brucellosis in humans and animals.

7. Kunda J, Fitzpatrick J, French N, Kazwala R, Kambarage D, Mfinanga GS, et al. Quantifying risk factors for human brucellosis in Rural Northern Tanzania. PLoS One. 2010;5(4).

8. Nabukenya I, Kaddu-Mulindwa D, Nasinyama GW. Survey of Brucella infection and malaria among Abattoir workers in Kampala and Mbarara Districts, Uganda. BMC Public Health [Internet]. BMC Public Health; 2013;13(1):901 PubMed . Available from: http:/ / bmcpublichealth.biomedcentral.com/articles/10.1186/1471-2458-13-901

9. Kyebambe PS. Case Reports Acute brucella meningomyeloencephalo - spondylosis in a teenage male. Afr Health Sci. 2005;5(1):69-72. PubMed

10. Mantur BG, Mulimani MS, Bidari LH, Akki AS, Tikare $\mathrm{N} \mathrm{V}$. Bacteremia is as unpredictable as clinical manifestations in human brucellosis. Int J Infect Dis. 2008;12(3):3037. PubMed

11. Mantur B, Parande A, Amarnath S, Patil G, Walvekar $\mathrm{R}$, Desai A, et al. ELISA versus conventional methods of diagnosing endemic brucellosis. Am J Trop Med Hyg. 2010;83(2):314-8.

12. Casañ as MC, Queipo-Ortuñ o MI, Rodriguez-Torres A, Ordun a A, Colmenero JD, Morata P. Specificity of a Polymerase Chain Reaction Assay of a Target Sequence on the 31-Kilodalton Brucella Antigen DNA Used to Diagnose Human Brucellosis. J Clin Microbiol. 2001;20:127-31. PubMed

13. Mantur B G, Amarnath SK SR. Review of clinical 
and laboratory features of human brucellosis. Vet Microbiol. 2007;25(3):188-202. PubMed

14. Al-Anazi K, Al-Jasser A. Brucellosis: A Global Re-emerging Zoonosis History, Epidemiology, Microbiology, Immunology and Genetics. EsciencecentralOrg [Internet]. 2014;1-10. Available from: http://esciencecentral.org/ebooks/bacterial-mycotic-infections/pdf/ brucellosis-3.pdf\%5Cnhttp:/ / esciencecentral.org/ebooks/bacterial-mycotic-infections/pdf/brucellosis1.pdf 15. Araj GF, Kattar MM, Fattouh LG, Bajakian KO, Kobeissi SA. Evaluation of the PANBIO Brucella immunoglobulin $\mathrm{G}(\operatorname{Ig} G)$ and IgM enzyme-linked immunosorbent assays for diagnosis of human brucellosis. Clin Diagn Lab Immunol. 2005;12(11):1334-5.

16. Asaad AM, Alqahtani JM. Serological and molecular diagnosis of human brucellosis in Najran, Southwestern Saudi Arabia. J Infect Public Health [Internet]. King Saud Bin Abdulaziz University for Health Sciences; 2012;5(2):189-94. Available from: http://dx.doi. org/10.1016/j.jiph.2012.02.001

17. Nasinyama G, Ssekawojwa E, Opuda J, Grimaud P, Etter E BA. Brucella sero-prevalence and modifiable risk factors among predisposed cattle keepers and consumers of un-pasteurized milk in Mbarara and Kampala districts , Uganda Abstract: Afr Health Sci. 2014;14(4):790-796.

18. Mutanda L. Selected laboratory tests in febrile patients in Kampala, Uganda. East Afr Med J. 1998;75(2):68-72. PubMed

19. Mugizi DR, Boqvist S, Nasinyama GW, Waiswa C, Ikwap K, Rock K, et al. Prevalence of and factors asso- ciated with Brucella sero-positivity in cattle in urban and peri-urban Gulu and Soroti towns of Uganda. J Vet Med Sci. 2015;1-8. PubMed

20. Apac statistical abstract. Apac district local government statistical abstract. UBOS. 2012;(June).

21. Gulu statistical abstract. The republic of Uganda Gulu district local government. UBOS. 2013;(June).

22. Lira statistical abstract. The republic of Uganda Lira district local governmentpa. UBOS. 2012;(June).

23. Pader statistical abstract. Higher local government statistical abstract Pader district P. O Box 1 , Pader-Uganda. UBOS. 2009;1(June).

24. Pourhoseingholi MA, Vahedi M, Rahimzadeh M. Sample size calculation in medical studies. Gastroenterol Hepatol from Bed to Bench. 2013;6(1):14-7.

25. Sayyad S, Malak MM, Miri BA, Gharib SM and VA. The Prevalence Rate of Human Brucellosis in Sanandaj County, West of Iran. Life Sci J. 2014;11(3s):23-5.

26. Yohannes M, Gill JP. Seroepidemiological survey of human brucellosis in and around Ludhiana, India. Emerg Health Threats J. 2011;4:1-7.

27. Makita K, Fèvre EM, Waiswa C, Kaboyo W, Eisler MC and WSC. Spatial epidemiology of hospital-diagnosed brucellosis in Kampala , Uganda. Int J Health Geogr. BioMed Central Ltd; 2011;10(1):52. PubMed

28. Ahmed MO, Elmeshri SE, Abuzweda AR, Blauo M, Abouzeed YM, Ibrahim A, et al. Seroprevalence of brucellosis in animals and human populations in the western mountains region in Libya , December 2006 - January 2008. Euro surveill. 2010;15(30):1-4. 